\title{
Pelatihan Dengan Pola "Sekolah Kader Calon Pemimpin" Bagi Kader Muhammadiyah Se Kabupaten Jember
}

\author{
Dhian Wahana Putra, Abdul Jalil \\ Universitas Muhammadiyah Jember \\ e-mail: dhianwahana@unmuhjember.ac.id, "abduljalil@unmuhjember.ac.id
}

Diterima: Maret 2021 | Dipublikasikan: Juni 2021

\begin{abstract}
ABSTRAK
Kader Muhammadiyah harus memiliki tiga kompetensi utama, yaitu kompetensi keagamaan, kompetensi kepemimpinan dan kompetensi akademik. Kompetensi tersebut idealnya menjadi kepribadian setiap kader Muhammadiyah, terutama bagi kader calon pimpinan. Kader calon pimpinan merupakan anggota inti persyarikatan Muhammadiyah yang mempunyai tugas dan tanggung jawab sebagai pelopor, pelangsung dan penyempurna Amal Usaha Muhammadiyah serta menggerakkan Muhammadiyah melalui jalur struktural. Kegiatan pelatihan dengan pola "Sekolah Kader Calon Pemimpin" bagi kader Muhammadiyah se Kabupaten Jember ini bertujuan untuk: (1) Meningkatkan kompetensi utama, yakni kompetensi keagamaan, kompetensi kepemimpinan, dan kompetensi akademik bagi kader Muhammadiyah di Kabupaten Jember, (2) Meneguhkan ideologi bagi kader Muhammadiyah di Kabupaten Jember untuk menyiapkan kader calon pimpinan. Pelatihan dalam kegiatan ini dilakukan sebanyak 12 kali pertemuan melalui kelas online, dengan metode ceramah, diskusi, demonstrasi, dan latihan (tutorial). Hasil survey awal menunjukkan kompetensi utama mitra pengabdian pada tingkat sedang. Setelah pelatihan dengan pola sekolah kader calon pemimpin ini selesai, maka dilakukan survey akhir hasilnya menunjukkan setiap parameter kompetensi utama, yaitu kompetensi keagamaan, kepemimpinan, dan akademik mengalami peningkatan. Setiap akhir pertemuan dilakukan monitoring dan evaluasi kepada calon kader pimpinan untuk mengukur capaian kompetensi pelatihan. Hasil pelatihan ini mampu memberi motivasi kepada peserta pelatihan yakni calon kader pimpinan dalam mencapai tujuan pelatihan yang telah ditetapkan.
\end{abstract}

Kata kunci: Pelatihan, Kader, Pemimpin

\section{ABSTRACT}

A muhammdiyah's cadre must have three main components, namely religious competence, leadership competence and academic competence. Three components above must be personalities of each Muhammadiyah cadre, especially for the cadre candidates for leadership. The cadre candidates for leadership are core members of the Muhammadiyah organization who have the duties and responsibilities as the pioneer, organizer and perfectionist of Muhammadiyah's Charitable Enterprises and mobilize Muhammadiyah through structural channels. This training activity with the pattern of "Leadership of New Generation" for Muhammadiyah cadres throughout Jember Regency aims to: (1) Improve the main competencies, namely religious competence, leadership competence, and academic competence for Muhammadiyah cadres in Jember Regency, (2) Strengthening ideology for Muhammadiyah cadres in Jember Regency to prepare cadres for leadership candidates. The training in this activity was conducted in 12 meetings through online classes, with the methods of lectures, discussions, demonstrations, and exercises (tutorials). The results of the preliminary survey demonstrate the main competencies of the community service partners at a moderate level. After the training with the pattern leadership of new generarion was completed, a final survey was conducted. The results demonstrated that each main competency parameter, namely religious, leadership, and academic competencies had increased. At the end of each meeting, is conducted monitoring and evaluation to leadership of new generation for Muhammadiyah's Cadre of Jember to measure the achievement of training competencies. The results of this training are able to motivate the training participants, namely leadership cadres in achieving the stated training objectives.

Keywords: Training, Cadre, Leadership 


\section{PENDAHULUAN}

Kaderisasi merupakan program dan kegiatan Muhammadiyah yang tidak akan pernah kunjung selesai (never ending job). Disamping itu pelaksanaan misi dan program kerja persyarikatan membutuhkan peran dan fungsi kader yang kompeten, militan, amanah, dan istiqamah. Terkait dengan hal itu, maka kebutuhan terhadap pendidikan kader yang sistematis, dan fleksibel tidak dapat ditunda-tunda lagi. Pelatihan dengan pola "Sekolah Kader Calon Pimpinan" menjadi kebutuhan persyarikatan ditengah dinamika masyarakat.

Substansi tentang perkaderan, sebagaimana pernyataan Mukti Ali, yaitu: baik buruknya organisasi Muhammadiyah pada masa yang akan datang dapat dilihat dari baik-buruknya pendidikan kader yang sekarang ini dilakukan. Jika pendidikan kader Muhammadiyah sekarang ini baik, maka Muhammadiyah pada masa yang akan datang akan baik. Sebaliknya apabila jelek maka Muhammadiyah pada masa yang akan datang juga jelek (BPK PP Muhammadiyah, 1993).

Majelis Pendidikan Kader (MPK) merupakan sebuah majelis yang mempunyai tanggungjawab dalam melakukan pembinaan Ideologi kader, agar kelak menjadi generasi Muhammadiyah siap sebagai pelopor dan pelangsung perjuangan persyarikatan. Berdasarkan rasionalisasi tersebut, maka penting untuk menyelenggarakan perkaderan fungsional, yang bertajuk sekolah kader pimpinan, baik pimpinan persyarikatan maupun pimpinan amal usaha. Kewajiban dan tanggungjawab moril untuk menaruh kepedulian terhadap kader dan perkaderan ini tidak berbeda dengan peringatan Allah SWT bagi umat Islam agar memperhatikan anak keturunan atau generasi pelanjutnya. Hal ini dinyatakan dalam Q.S An Nisa: 9 sebagai berikut:

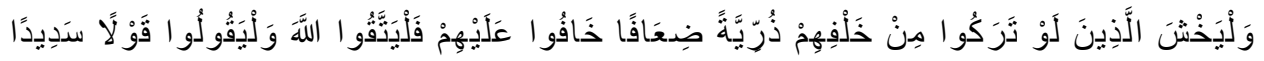

Dan hendaklah takut kepada Allah orang-orang yang seandainya meninggalkan dibelakang mereka anak-anak yang lemah, yang mereka khawatir terhadap (kesejahteraan) mereka. Oleh sebab itu hendaklah mereka bertakwa kepada Allah dan hendaklah mereka mengucapkan perkataan yang benar. (Q.S An Nisa: 9)

Kader Muhammadiyah yang ideal harus memiliki 4 (empat) kompetensi yaitu: (1) Kompetensi keberagamaan (2) Kompetensi akademis dan intelektual, (3) Kompetensi sosial kemanusiaan dan kepeloporan dan (4) Kompetensi keorganisasian dan kepemimpinan. Saat ini mitra pengabdian sangat kesulitan untuk menemukan kader Muhammadiyah yang mampu memiliki 4 (empat) kompetensi tersebut. Apalagi dalam masa pandemi COVID 19 ini proses perkaderan dan peneguhan Ideologi Muhammadiyah idealnya tidak boleh berhenti, dengan kata lain proses perkaderan dan penguatan Ideologi Muhammadiyah harus dilakukan dalam keadaan bagaimanapun. Pelatihan dengan pola sekolah kader, bagi persyarikatan Muhammadiyah menjadi sangat penting dan strategis mengingat misi dan eksistensi Muhammadiyah sebagai Gerakan Islam, Dakwah Amar Ma'ruf Nahi Munkar dan Tajdid, bersumber pada Al Qur'an dan As Sunnah (Anggaran Dasar Dan Anggaran Rumah Tangga Muhammadiyah, 2005). Selain itu pelatihan dengan pola sekolah kader calon pimpinan ini, akan menjadi solusi bagi mitra dalam mengatasi krisis kompetensi kader.

\section{METODE PEIAKSANAAN}

Kegiatan "Sekolah Kader Calon Pemimpin" ini merupakan pengabdian kepada masyarakat yang dilaksanakan menggunakan metode pelatihan dan pembinaan kepada kader Muhammadiyah se Kabupaten Jember. Pelaksanaan kegiatan ini secara rutin setiap hari sabtu selama 12 kali tatap muka. Materi pelatihan disusun secara sistematis agar peserta memahami substansi kegiatan secara holistik. Sasaran kegiatan pengabdian ini adalah sebagai berikut: 


\begin{tabular}{|c|c|c|}
\hline UNSUR & KRITERIA & $\begin{array}{c}\text { JUMLAH } \\
\text { DELEGASI }\end{array}$ \\
\hline $\begin{array}{l}\text { Pimpinan Cabang } \\
\text { Muhammadiyah/Aisyiyah (PCM/A) }\end{array}$ & $\begin{array}{l}\text { 1. Bukan ketua PCM } \\
\text { 2. Dapat dari unsur } \\
\text { majelis } \\
\text { 3. Usia dibawah } 50 \\
\text { tahun }\end{array}$ & $\begin{array}{l}\text { Masing-masing } \\
\text { PCM/A } 2 \text { orang }\end{array}$ \\
\hline $\begin{array}{l}\text { Amal Usaha Muhammadiyah/Aisyiyah } \\
\text { (AUM/A) Bidang Pendidikan }\end{array}$ & $\begin{array}{l}\text { 1. Bukan Kepala } \\
\text { Sekolah } \\
\text { 2. Berstatus sebagai } \\
\text { Guru Tetap } \\
\text { 3. Usia tidak lebih dari } \\
55 \text { tahun }\end{array}$ & $\begin{array}{l}\text { Masing-masing } \\
\text { sekolah } 2 \text { orang }\end{array}$ \\
\hline \multicolumn{2}{|c|}{ Total Peserta } & 250 orang \\
\hline
\end{tabular}

Menurut (Kamil, 2003) Pelatihan sebagai sebuah konsep program yang bertujuan untuk meningkatkan pengetahuan dan keterampilan seseorang (sasaran didik). Adapun tahapan-tahapan yang dilalui dalam pelaksanaan pengabdian ini dibagi menjadi tiga tahapan, pertama adalah persiapan, kedua pelaksanaan, dan ketiga adalah evaluasi dan laporan. Masing-masing tahapan memiliki Langkah-langkah yang berksinambungan guna mencapai tujuan dari pengabdian itu sendiri. Masing-masing tahapan akan diuraikan sebagai berikut:

Tahap Persiapan

Dalam tahap ini kami melakukan koordinasi dengan Majelis Pendidikan Kader (MPK) PDM Kab. Jember. Koordinasi ini kami lakukan sekaligus sebagai observasi dan identifikasi permasalahann yang dihadapi oleh mitra yakni Majelis Pendidikan Kader (MPK) dalam melaksanakan tugas-tugas mendidik kader. Akhirnya ditemukan permasalahan bahwa kader persyarikatan dilingkungan Muhammadiyah perlu dibekali kompetensi kepemimpinan, untuk membekali mereka sebagai pimpinan di persyarikatan maupun pimpinan di Amal Usaha Muhammadiyah (AUM) bidang pendidikan, dalam hal ini sekolah/madrasah/pesantren Muhammadiyah se Kab. Jember.

Setelah tim pengabdian menemukan permasalahan yang dihadapi oleh mitra, maka tim melakukan koordinasi internal untuk menyusun maping (identifikasi masalah secara spesifik), secara spesifik masalah yang akan diselesaiakan adalah kompetensi keagamaan dan ideologi, serta kompetensi kepemimpinan. Selanjutnya menentukan sasaran, strategi dan pola sebagai langkah solutif atas permasalahan mitra, sekaligus pada tahapan ini tim pengabdian melakukan pembagian tugas sesuai dengan kompetensinya masing-masing.

\section{a. Tahap Pelaksanaan}

Kegiatan pengabdian ini dilaksanakan setiap hari sabtu, sejak tanggal 14 November 2020 hingga Sabtu 30 Januari 2021, total waktu selama 2,5 bulan. Kegiatan pelatihan dengan pola sekolah kader ini dilaksanakan secara online melalui ruang virtual zoom. Pemateri juga telah kami jadwal sesuai dengan kompetensi masing-masing. Berikut ini jadwal lengkap kegiatan pengabdian ini: 


\begin{tabular}{|c|c|c|}
\hline WAKTU & MATERI & PEMATERI \\
\hline $\begin{array}{l}\text { Pertemuan ke 1, } \\
\text { Sabtu, } 14 \text { November } 2020 \\
\text { Pukul 13.00-15.00 }\end{array}$ & $\begin{array}{l}\text { Launching Program Sekolah Kader } \\
\text { Pimpinan \& Orientasi umum Kegiatan }\end{array}$ & $\begin{array}{l}\text { Ketua MPK PWM } \\
\text { Ketua PDM Jember } \\
\text { Dhian Wahana Putra, } \\
\text { M.Pd.I } \\
\text { Abd. Jalil, S.P }\end{array}$ \\
\hline $\begin{array}{l}\text { Pertemuan ke 2, } \\
\text { Sabtu, } 21 \text { November } 2020 \\
\text { Pukul 13.00-15.00 }\end{array}$ & $\begin{array}{l}\text { Materi } 1 \\
\text { Posisi Ideologi Muhammadiyah } \\
\text { ditengah Pusaran Ideologi Lain }\end{array}$ & $\begin{array}{l}\text { Prof. Dr. Haedar } \\
\text { Nashir, M.Si }\end{array}$ \\
\hline $\begin{array}{l}\text { Pertemuan ke 3, } \\
\text { Sabtu, } 28 \text { November } 2020 \\
\text { Pukul 13.00-15.00 }\end{array}$ & $\begin{array}{l}\text { Materi } 2 \\
\text { Faham Agama Dalam Muhammadiyah }\end{array}$ & $\begin{array}{l}\text { Fathurrahman } \\
\text { Kamal, Lc, M.S.I }\end{array}$ \\
\hline $\begin{array}{l}\text { Pertemuan ke 4, } \\
\text { Sabtu, } 5 \text { Desember } 2020 \\
\text { Pukul 13.00-15.00 }\end{array}$ & $\begin{array}{l}\text { Materi } 3 \\
\text { Kepemimpinan Transformatif K.H } \\
\text { Ahmad Dahlan }\end{array}$ & $\begin{array}{l}\text { Prof. Dr. Abd Mu'ti, } \\
\text { M.Ed }\end{array}$ \\
\hline $\begin{array}{l}\text { Pertemuan ke } 5 \\
\text { Sabtu, } 12 \text { Desember } 2020 \\
\text { Pukul 13.00-15.00 }\end{array}$ & $\begin{array}{l}\text { Materi } 4 \\
\text { Muqaddimah AD Muhammadiyah: } \\
\text { Aktualisasi Nilai Karakter Pimpinan }\end{array}$ & $\begin{array}{l}\text { Najib Hamid, S.Sos, } \\
\text { M.Si }\end{array}$ \\
\hline $\begin{array}{l}\text { Pertemuan ke } 6 \\
\text { Sabtu, } 19 \text { Desember } 2020 \\
\text { Pukul 13.00-15.00 }\end{array}$ & $\begin{array}{l}\text { Materi 5 } \\
\text { Kompetensi Pimpinan Persyarikatan } \\
\text { dan AUM: Kompetensi Religius dan } \\
\text { Humanitas (Aqidah, Ibadah, Akhlak, } \\
\text { dan Mu'amalah) }\end{array}$ & $\begin{array}{l}\text { Dr. Syamsul Hidayat, } \\
\text { M.Ag }\end{array}$ \\
\hline $\begin{array}{l}\text { Pertemuan ke } 7 \\
\text { Sabtu, } 26 \text { Desember } 2020 \\
\text { Pukul 13.00-15.00 }\end{array}$ & $\begin{array}{l}\text { Materi } 6 \\
\text { Sinergi Pimpinan Persyarikatan dan } \\
\text { Pimpinan AUM: Membentuk Sekolah } \\
\text { Unggul }\end{array}$ & $\begin{array}{l}\text { Prof. Dr. Biyanto, } \\
\text { M.Ag }\end{array}$ \\
\hline $\begin{array}{l}\text { Pertemuan ke 8, } \\
\text { Sabtu, } 2 \text { Januari } 2021 \\
\text { Pukul 13.00-15.00 }\end{array}$ & $\begin{array}{l}\text { Materi } 7 \\
\text { Kepribadian Muhammadiyah adalah } \\
\text { Kepribadian Pimpinan } \\
\text { Muhammadiyah }\end{array}$ & $\begin{array}{l}\text { Prof. Dr. Thohir } \\
\text { Luth, M.A }\end{array}$ \\
\hline $\begin{array}{l}\text { Pertemuan ke 9, } \\
\text { Sabtu, } 9 \text { Januari } 2021 \\
\text { Pukul 13.00-15.00 }\end{array}$ & $\begin{array}{l}\text { Materi } 8 \\
\text { Theologi Al Ma'un: Mewujudkan } \\
\text { Kemandirian Persyarikatan Dan } \\
\text { Sekolah Berbasis Wirausaha }\end{array}$ & $\begin{array}{l}\text { Dr. Sulthon Amien, } \\
\text { M.M }\end{array}$ \\
\hline $\begin{array}{l}\text { Pertemuan ke 10, } \\
\text { Sabtu, } 16 \text { Januari } 2021 \\
\text { Pukul 13.00-15.00 }\end{array}$ & $\begin{array}{l}\text { Materi } 9 \\
\text { Kolaborasi Pimpinan Persyarikatan } \\
\text { dan Sekolah Muhammadiyah: } \\
\text { Mewujudkan Kader Sehat }\end{array}$ & $\begin{array}{l}\text { dr. Achmad } \\
\text { Shochibul Birri, } \\
\text { M.SI, M.M.R }\end{array}$ \\
\hline $\begin{array}{l}\text { Pertemuan ke 11, } \\
\text { Sabtu, } 23 \text { Januari } 2021 \\
\text { Pukul 13.00-15.00 }\end{array}$ & $\begin{array}{l}\text { Materi 10 } \\
\text { Mempertahankan Ideologi } \\
\text { Muhammadiyah: Strategi Aksi } \\
\text { Pimpinan ditengah Masyarakat yang } \\
\text { Berubah }\end{array}$ & $\begin{array}{l}\text { Dr. Saad Ibrahim, } \\
\text { M.A }\end{array}$ \\
\hline $\begin{array}{l}\text { Pertemuan ke 12, } \\
\text { Sabtu, 30 Januari } 2021 \\
\text { Pukul 13.00-15.00 }\end{array}$ & $\begin{array}{l}\text { Materi } 11 \\
\text { Epilog: Penguatan dan } \\
\text { Pengarusutamaan Program Sekolah } \\
\text { Kader Pimpinan }\end{array}$ & $\begin{array}{l}\text { Dhian Wahana Putra, } \\
\text { M.Pd.I } \\
\text { Abd. Jalil, S.P }\end{array}$ \\
\hline
\end{tabular}




\section{b. Tahap Evaluasi dan Laporan}

Pada tahapan evaluasi ini kami membagi menjadi dua metode. Pertama, evaluasi setelah materi disampaikan oleh pemateri, yang kami evaluasi adalah capaian dan serapan materi. Kami melakukan evaluasi dengan cara melakukan tes menggunakan soal evaluasi dengan google form. Kedua, sebagai bagian dari evaluasi, kami melakukan tindak lanjut dari kegiatan ini dengan terus membangun komunikasi dengan mitra untuk mengetahui perkembangan kompetensi kader calon pimpinan secara umum..

\section{HASIL KEGIATAN}

Berdasarkan identifkasi masalah yang penulis temukan pada saat observasi awal sebelum pelaksanaan pengabdian dan masalah yang ditemui pada saat pelaksanaan pengabdian terdapat persamaan. Lemahnya kompetensi keberagamaandan ideologi, serta kompetensi kepemimpinan dan keorganisasian bagi kader calon pimpinan pada sasaran mitra menjadi persoalan yang utama.

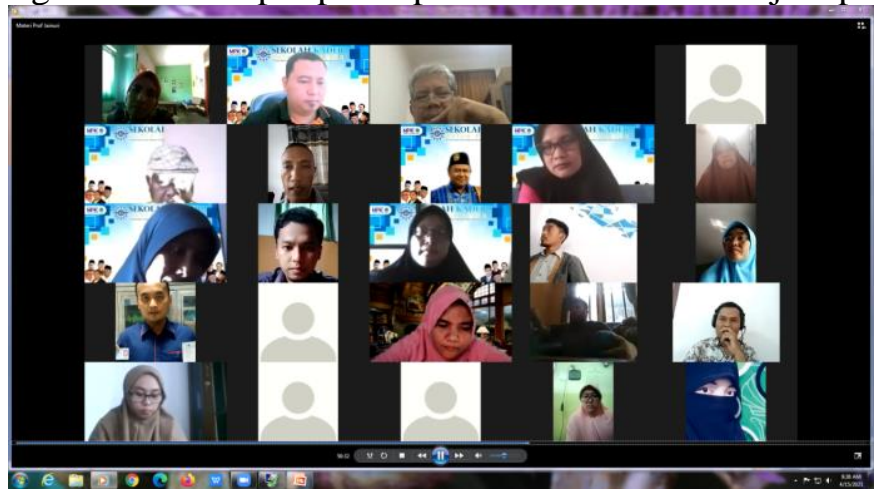

1. Kompetensi Keberagamaan dan Ideologi

Dalam buku sistem perkaderan Muhammadiyah (Majelis Pendidikan Kader PP Muhammadiyah, 2005) disebutkan bahwa keberagamaan dan ideologi merupakan kompetensi utama sebagai kader Muhammadiyah. Pada kompetensi ini memuat 6 (enam) standar kompetensi, yaitu: pertama, kemurnian aqidah (keyakinan berbasis tauhid yang bersumber pada ajaran Al Qur'an dan Sunnah Nabi yang shahih/maqbullah) yang membntuk keshalehan dalam kehidupan. Kedua, Ketaatan beribadah (senantiasa menjalakan ibadah mahdhah, baik yang wajib maupun yang sunnah tathawwu' sesuai tuntunan Rasulullah) yang tahsinah (kemanfaatan atau fungsi) dari ibadah itu terpantul dalam kehidupan sehari-hari. Ketiga, keikhlasan (melakukan sesuatu semata-mata karena Allah SWT) dalam hidup dan berjuang menegakkan ajaran Islam melalui Muhammadiyah. Keempat, Shiddiq (Jujur dan dapat dipercaya) dalam hati, kata, dan tindakan. Kelima, Amanah (komitmen dan tanggungjawab moral) dalam mengemban tugas organisasi. Keenam, Berjiwa gerakan (semangat untuk aktif dalam Muhammadiyah sebagai panggilan jihad di jaan Allah)

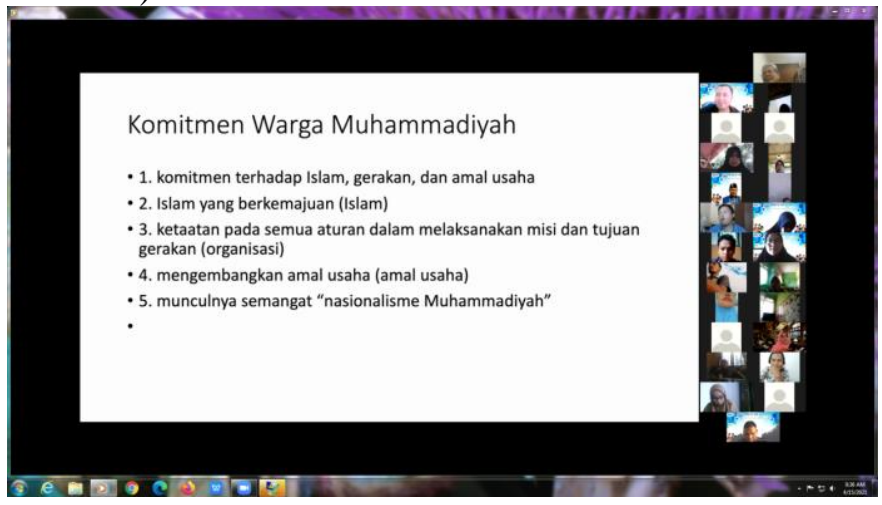




\section{Kompetensi Kepemimpinan}

Dalam buku sistem perkaderan Muhammadiyah (Majelis Pendidikan Kader PP Muhammadiyah, 2005), kompetensi kepemimpinan dan keorganisasian dicirikan dengan nilainilai sebagai berikut: Pertama, pengkhidmatan da partisipasi aktif dalam peran keumatan, kebangsaan, dan kemanusiaan universal. Kedua, menempati posisi apapun dengan semangat ikhlas, berdedikasi, berprestasi, dan menghasilkan hal-hal terbaik. Ketiga, menjadi bagian yang menyatu dengan denyut nadi kehidupan persyarikatan, ummat, dan bangsa sebagai wujud menjalankan misi organisasi. Keempat, berkomitmen dan menjunjung tinggi ideologi Muhammadiyah dan mampu bersikap tegas tetapi arif dalam membela serta menegakkan prinsip dan kepentingan perstarikatan. Kelima, mengutamakan misi dan kepentinga Muhammadiyah diatas lainnya dengan niat ikhlas dan berkhidmat.

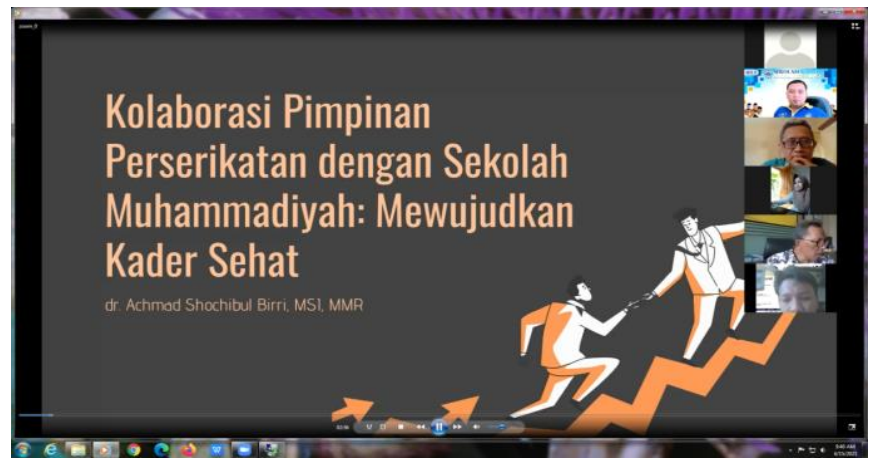

\section{KESIMPULAN DAN SARAN}

Serangkaian kegiatan pengabdian yang kami lakukan dapat disimpulkan bahwa peserta kegiatan sekolah kader sangat antusias, dan selama kegiatan berlangsung sangat interaktif dengan pemateri. Pemateri memaparkan materi berusaha menyesuaikan dengan fakta yang terjadi sehingga sajian materi sangat aktual. Sepanjang pantauan kami dan berdasarkan pada hasil capaian materi, peserta sangat memahami apa yang disampaikan oleh penyaji. Selain itu peserta semakin termotivasi untuk menggerakkan Muhammadiyah sebagai kader calon pimpinan. Kedepan program serupa baik untuk dilanjutkan sebagai wujud meningkatkan Sumber Daya Manusia (SDM) kader Muhammadiyah agar siap menjadi pelopor, pelangsung dan penyempurna amal usaha muhammadiyah.

\section{UCAPAN TERIMA KASIH}

Pelaksanaan kegiatan pengabdian ini berjalan dengan lancar, oleh karena itu kami mengucapkan terimakasih kepada: Mitra pengabdian (Majelis Pendidikan Kader, PDM Kab. Jember), Lembaga Penelitian dan Pengabdian pada Masyarakat (LPPM) UM Jember atas supportnya.

\section{DAFTAR PUSTAKA}

BPK PP Muhammadiyah. (1993). Tanfidz Keputusan Rakerpim BPK PP Muhammadiyah. Suara Muhammadiyah.

Kamil, M. (2003). Model-Model Pelatihan. Universitas Pendidikan Indonesia.

Majelis Pendidikan Kader PP Muhammadiyah. (2005). Sistem Perkaderan Muhammadiyah. MPK PP Muhammadiyah.

Anggaran Dasar Dan Anggaran Rumah Tangga Muhammadiyah, PUB. L. NO. Keputusan Muktamar Muhammadiyah Ke 45, 1 (2005). 